\title{
ORNITHOLOGY
}

\section{Birds in Winter: Surviving the Most Challenging Season}

Roger F. Pasquier. Illustrated by Margaret La Farge. 2019. Princeton University Press. 304 pages, 29.95 USD, Cloth or E-book.

Full disclosure: I like books that deal with a broad topic in Ornithology, and I especially like ones that treat that topic from a natural history perspective, so I began with a positive bias towards this book. From the title, and also from the cover picture, showing a crossbill perched on a snowy branch, I anticipated that it would be mostly about how birds

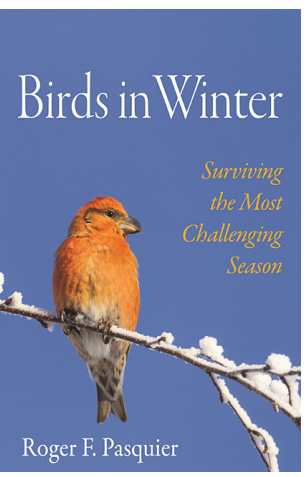
cope with tough physical conditions in winter at high latitudes. That material is here, but there is much, much more. This is a very wide-ranging volume.

The book begins by describing migration as a strategy for avoiding cold weather and short days and continues with a discussion of food caching for winter survival, the ecology of migrants in their wintering areas, and the maintenance of territories and winter flocking behaviour among wintering birds, both resident and migrant; strategies to cope with cold weather and short days do not get much attention until 120 pages in. Following two chapters on the rigours of high latitude winters (Survival, The Winter's Day) the author moves to preparations for spring and departure from the wintering grounds. The book concludes with a chapter on conservation and a chapter on climate change and its observed and predicted impacts.

The many topics covered are reflected in the author's recourse to a very large number of references: more than 600 are cited, of which about half are dated after 2000, so this is a pretty up-to-date account. There is a very judicious combination of broad generalizations and specific examples. For instance, we are told, "For many birds, direct competition [in winter] is reduced or avoided when each sex and age group differs in habitat choice, feeding specialty, anatomy or winter range" (p. 63). This generalization is then ex- emplified by three Scandinavian owls that have contrasting migration strategies. It is inevitable that some generalizations provoke counterexamples in the mind of the reviewer, but I found few that I disagreed with entirely and many that I found useful and thoughtprovoking. This book would be an excellent source of ideas around which to develop hypotheses and tests for any graduate student thinking about doing a project relating to migrant birds.

Unfortunately, an inevitable result of covering so many topics is that the text is very dense with facts and this does make reading hard going in some places. This is not really a book to read straight through, but rather one to dip into for particular topics. Another small reservation I had about the book concerns the illustrations, by Margaret La Farge. They are well designed to complement the text, but some combination of paper and printing seems to have reduced the clarity for some of them. It is worth noting that the publisher's claim: "Birds in Winter is the first book devoted to the ecology and behavior of birds during this most challenging season", is not strictly true, as a book by Jennifer VanVoorst with the same title was published in 2016 (Bullfrog Books). However, that is a children's book, designed as a teaching aid.

I thought I knew plenty about winter challenges for birds, but the book made me appreciate the huge ramifications winter has for the feathered tribe. Even birds that never leave the tropics feel the competition from migrants that spend more than half the year in their habitats. Surprisingly, considering the importance of the subject, the statement that this is the first general review of wintering in birds does appear to be true for adult natural history books, so this is a really welcome publication on a previously neglected topic. I found it a tremendous compilation of ideas and facts about wintering birds and I think it deserves to be very widely read.

TONY GASTON

Ottawa, ON, Canada

(C) The author. This work is freely available under the Creative Commons Attribution 4.0 International license (CC BY 4.0). 